\title{
COMMENT ON: LONG-TERM RENAL FUNCTION AFTER TREATMENT FOR UNILATERAL NON-SYNDROMIC WILMS' TUMOR BY GREEN ET AL. - A PERSONAL PERSPECTIVE.
}

Denis Cozzi ${ }^{1}$, SILVIA Ceccanti ${ }^{1}$, and Francesco Cozzi ${ }^{1}$

${ }^{1}$ Sapienza University of Rome

August 10, 2020

\section{Hosted file}

letter to green 2020.doc available at https://authorea.com/users/349812/articles/474801comment-on-long-term-renal-function-after-treatment-for-unilateral-non-syndromic-wilmstumor-by-green-et-al-a-personal-perspective 